Dr. Debroutelles, of Dieppe, writing to the Academy of Medicine, and recommending calomel in cholera, upon the strength of the freedom experienced at the Venereal Hospital, just as if calomel could not be recommended (as, for instance, on Dr. Ayre's suggestion) upon its own well-known action. A madman, named Provençal, house-physician at the Montpelier Hospital, writes, on the same subject, to the Academy, and proposes that the syphilitic virus should be inoculated, as a prophylactic of cholera! M. Velpeau remarked, in a late meeting of the Academy, that many of his colleagues had treated cholera patients affected with syphilis; and M.Gimelle added, that he had lately had under his care a young man of twenty-six, affected with chancre; he was taking proto-iodide of mercury for this affection, when he was carried off by cholera in a few hours. M. Ricord explicitly maintains, in a letter addressed to $L^{\prime}$ Union Médicale, on June 16, that neither syphilis nor mercury, nor the two influences combined, are proved to preserve from cholera. He attributes t..e immunity of the Hôpital des Vénériens to the comparatively few patients of the establishment, and its salubrious situation; and very aptly remarks, that the Maternity Hospital, situated only a few yards from his hospital, enjoys the same immunity from cholera. Thus, we find the two surgeons of the Hopital du Midi-viz., M. Vidal (de Cassis) and M. Ricord, differing widely on this subject. The latter gentleman enters into extremely interesting details in his letter. We regret that want of space forbids our entering more fully into the consideration of this important communication. Among the remedial neasures proposed, we must not omit M. Piorry's. This gentleman, considering that cholera patients die for want of water in the blood, had this liquid thrown, in large quantities, into the bladder of a man dying of the disease. No less than two quarts were injected in one hour, and absorption was rapidly proceeding, as ascertained by the plessimater: the pulse rose; the veins, which were almost empty, began to refill, and the man was improving; the ultimate result is not yet known. This fact was communicated to the Academy of Sciences on the 11th June: at the same meeting, some very interesting statements were made by M. Audrand, respecting the absence of electricity in the atmosphere, during the present epidemic. This gentleman has made his observations with a circular glass-plate machine, which, in ordinary times, gives sparks about an inch long, by two or three turns of the plate. $\mathrm{He}$ has been unable, since the breaking out of the epidemic, of once producing this result. In April and May, a great many turns were necessary to produce sparks of an inch, and the variations in the size of the sparks have accorded with the oscillations of the disease. During the very hot days, on the 4th, 5th, and 6th of June, nothing but crepitations, without sparks, could be obtained; on the 7 th, the machine could not be made to yield anything, (720 persons died on the 8th.) A few sparks re-appeared on the morning of the 8 th, and after the storm, which broke out on that day, numerous sparks could be obtained by the slightest touch of the plate.

M. Raspail, well known by his chemical works, and still better by his extreme politics, main tains that he can cure cholera with camphor, and the public of Paris are quite enthusiastic about the smoking of camphor cigarettes. These, our readers are aware, have been long recommended by $M$. Raspail as sovereign remedies in all diseases; and though there are no actual facts giving the slightest support to this method, as far as the present epidemic is concerned, it is reported that the author, who is locked up at Doullens, cannot reply to all the huge medical correspondence which he carries on from his prison. Numerous death from cholera, among medical men, have been reported: among them we find M. Bourgery, the author of the work entitled "LAnatomie de l'Homme," which, unfortunately, is left unfinished, and upon which twenty years' labour have been bestowed; M. Boudet, member of the Academy of Medicine; and M. Mojon, of Genoa, an eminent surgeon under Napoleon, and long settled in Paris. Professor Bouillaud is likewise reported to be suffering from a very severe attack of cholera. A little village of the department of the Oise, numbering about 2000 inhabitants, has been attacked both by the cholera and the sweating sickness; in a short time nearly 100 people had died. Medical men, hospital pupils, and sisters of charity, were speedily sent down from Paris, and their efforts, guided and organized by M. Mélier, a member of the Board of Health, who volunteered his attendance, are likely to do much good. A drunkard finding his wife dying of cholera, had the cruelty, whilst in a state of inebriety, to beat her violently. This rough usage, far from destroying her, as might be expected, roused her, brought on powerful reaction, and gaved her. This reminds us of the flagellations recommended in cases of poisoning by opium. The dissecting rooms of Clamart have been closed, by order of the Director of Hospitals, till the end of June, to prevent any insalubrious effects from the accumulation of subjects. The municipal body of Paris have voted $£ 6000$ for burial expenses, and $£ 2000$ for the extraordinary cholera dispensaries. The Council of the Bank of France have sent $£ 1000$ to the Prefect of the Seine, to be distributed to poor families bereft by cholera. Two large mansions belonging to the state, one lately occupied by General Cavaignac, the other by the Austrian ambassador, have been converted into cholera hospitals. Opinions are still at variance as to the contagious nature of cholera. A warm discussion took place on the subject the other day, at the Academy of Medicine, and it is but right that our readers should know, that so high an authority as M. Velpeau affirms that the disease is contagious. A contagionist medical practitioner of a certain village, having struck terror into the minds of the people, the sick remained without assistance, and the dead without burial, so much so that the clergyman was obliged to bury them himself. M. Mélier, who mentioned this circumstance in the Academy, promised to name the place to the cholera committee. Eating-houses and butchers' shops are being examined by the police, upon an order from the Board of Health.

\section{THE JOHN-HUNTER CLUB.} To the Editor of The LanceT.

SrR,-I yesterday received the enclosed communication from Mr. Wormald, who, as you will perceive, complains loudly of the injurious operation of a self-constituted body of fellows, calling themselves the John-Hunter CIub. The assumption of the name of John Hunter appears to be the least important of their proceedings; indeed, it becomes too evidently a more serious question in what way the operations of such an association should be counteracted by the fellows in general.

"It is come to my lmowledge," says Mr. Wormald, "that my introduction into the council will be opposed by this club." The eligibility of the candidate next on the list is, if $\mathbf{M r}$. Wormald's statements be correct, determined by some form of ballot, but it is an integral principle of the association that the majority should carry with them the minority, and so therefore, the full force of the entire club is uniformly brought to bear against the obnoxions candidate on the day of election. I should be glad if you could find me space enough in this week's LANCET to inquire whether any fellow be prepared with a plan calculated to counteract in some measure the vicious interference of this cabal with the fair and legitimate purposes for which the fellows have been invited to assemble on Thurs. day. Something must be done, or the non-clubbists may as well remain at home. The only method which suggests itself to me at this moment is the immediate formation of a counter coalition. I remain, Sir, your obedient servant,

Dorset-place, Dorset-square, June, 1849.

Henry Savage, M.D. Lond., F.R.C.S.E.

* * This note was accompanied by a copy of a circular from Mr. Wormald, to which we have given insertion in another place.-ED. L.

\section{To the Editor of THE LANCET.}

Sir,-The thanks of the profession are due to you for having, by the remarks in the last two numbers of your influential journal, given the death-blow to the doings and intentions of the "John-Hunter Club." But, Sir, it is due to the profession that the names of these conspirators, alike against its peace, honour, and independence, should be known; and I venture to affirm, than such an exposure would be quite sufficient to complete your work of demolition, if any remnant of this execrable and miserable piece of cliquism should still linger. Who are Mr. Soden, Mr. Charles Hawkins, and Mr. Richard Partridge, that they should pass a vote of condemnation upon Mr. Wormald, Mr. Pilcher, Mr. Bishop, and others? Have they been elevated to the censorship of the profession on-account of any advantages which their labours have conferred upon it? Let the names of other actors in this drama be bronght out; and then we shall know, when the time arrives, who are the men whose position in the council (if they get there) would seriously obstruct the spread of those principles which it has been your object as well as that of the great body of the profession to disseminate. I am, Sir, your obedient servant, June 25, 1849.
A Fellow. 